\title{
COGNITIVE THERAPY AND EXPOSURE IN VIVO IN THE TREATMENT OF OBSESSIVE COMPULSIVE DISORDER
}

\author{
PATRICIA VAN OPPEN, ${ }^{1 *}$ ELSE DE HAAN, ${ }^{2}$ \\ ANTON J. L. M. VAN BALKOM, ${ }^{1}$ PHILIP SPINHOVEN, ${ }^{3}$ \\ KEES HOOGDUIN ${ }^{4}$ and RICHARD VAN DYCK ${ }^{\prime}$
}

${ }^{1}$ Department of Psychiatry at the Amsterdam Psychiatric Centre, Vrije Universiteit, Valeriusplein 9, 1075 BG Amsterdam, The Netherlands, 'Psychiatric Outpatient Department, Delft, The Netherlands, ${ }^{3}$ Department of Psychiatry, University of Leiden, Oegstgeest, The Netherlands and ${ }^{4}$ Department of Clinical and Personality Pscyhology, Catholic University Nijmegen, Nijmegen, The Netherlands

(Received 24 June 1994)

\begin{abstract}
Summary-The present study is the first controlled study that evaluates the effects of cognitive therapy along the lines of Beck (1976) [Cognitive therapy and the emotional disorder. New York: International University Press] and Salkovskis (1985) [Behaviour Research and Therapy, 23, 571-583] in obsessive compulsive disorder (OCD) and compares these effects with those of self-controlled exposure in vivo with response prevention. Seventy-one patients were randomly assigned to either cognitive therapy or exposure in vivo. In each treatment condition seven patients dropped out. Both treatments consisted of 16 sessions. Cognitive therapy as well as exposure in vivo led to statistically significant improvement. Multivariate significant differences suggesting a superior efficacy of cognitive therapy in comparison to exposure in vivo on the obsessive compulsive measures and on the measures for associated psychopathology. However, no univariate differences were found. Further, in both treatment conditions a considerable percentage of the patients was rated as "recovered". Significantly more patients were rated as "recovered" in the cognitive therapy. The results show that this form of cognitive therapy is an effective treatment for OCD and suggest that cognitive therapy may be even more effective than exposure in vivo.
\end{abstract}

\section{INTRODUCTION}

Until the seventies obsessive compulsive disorder (OCD) was seen as a condition resistant to psychotherapy. During the last two decades several studies have shown that exposure in vivo plus response prevention is an effective treatment of OCD (Emmelkamp, 1982; Marks, 1987; Rachman \& Hodgson, 1980; Steketee, 1993). In recent years, a substantial number of studies have demonstrated the effectiveness of cognitive therapy for anxiety disorders (e.g. Hollon \& Beck, 1994; Margraf, Barlow, Clark \& Telch, 1993). A relatively small number of studies have addressed the issue of cognitive treatment with obsessive compulsives. Until now only three controlled studies have investigated the effectiveness of cognitive therapy with OCD.

The first controlled study on the effect of cognitive therapy was conducted by Emmelkamp, van der Helm, van Zanten and Plochg (1980). This study investigated whether self-instructional-training (Meichenbaum, 1975) could enhance the effectiveness of exposure in vivo plus response prevention. In the cognitive restructuring group patients were trained to become conscious of the negative self-statements and then to substitute positive coping self-statements for the anxiety-engendering self-statements. The results of this study indicate that self-instructional training did not increase therapeutic efficacy (Emmelkamp et al., 1980). However, Kendall (1983) doubted if self-instructional training is the most appropriate cognitive technique for patients who are already engaging in self-verbalizations, ruminations and doubting. Cognitive treatment that addresses deeper cognitive structures might be more effective in dealing with obsessive compulsive symptoms (McFall \& Wollersheim, 1979).

In a following study (Emmelkamp, Visser \& Hoekstra, 1988) the effects of rational emotive therapy (RET) along the lines of Ellis (1962) were compared with those of self-controlled exposure in vivo plus response prevention. In the RET group patients were trained to record their (irrational)

*Author for correspondence. 
thoughts and to challenge these irrational beliefs; behavioural experiments were not included. On the obsessive compulsive targets, and on social anxiety, RET was equally effective as self-controlled exposure in vivo plus response prevention. On depression, however, RET was more effective than self-controlled exposure in vivo plus response prevention.

Finally, a third study that evaluated the effects of cognitive therapy was reported by Emmelkamp and Beens (1991). They investigated two issues:

(1) whether RET was as effective as self-controlled exposure in vivo plus response prevention; and

(2) whether a combined package would be superior to exposure in vivo with response prevention.

No difference was found between RET and self-controlled exposure in vivo plus response prevention and the combined treatment was no more effective than self-controlled exposure alone.

To date, only one single case study (Salkovskis \& Warwick, 1985) has illustrated the use of cognitive therapy according to the model of Beck and Salkovskis. The primary aim of the present study was to evaluate the effects of a version of cognitive therapy along the lines of Beck (1976) and Salkovskis (1985), specifically developed for OCD (van Oppen \& Arntz, 1994) and to compare the effects of cognitive therapy with those of self-controlled exposure in vivo plus response prevention on obsessive compulsive targets and on more generalized measures for associated psychopathology. The secondary aim of this study was to investigate the efficacy of six sessions of cognitive therapy without behavioural experiments vs six sessions of exposure in vivo with response prevention without discussing the expectations of consequences in OCD. This version of cognitive therapy aimed at modifying: (i) overestimation of danger; and (ii) inflated responsibility. Previous studies found self-controlled exposure as effective as therapist-controlled exposure (Emmelkamp \& Kraanen, 1977; Emmelkamp, van Linden van den Heuvell, Ruphan \& Sanderman, 1989). Therefore we used self-controlled exposure in vivo instead of therapist-controlled exposure in vivo in this study.

\section{METHOD}

\section{Design}

Approximately half of the patients took part in a multicentre trial comparing fluvoxamine, behaviour therapy and cognitive therapy, results of which will be presented elsewhere. The number of patients in the cognitive therapy and exposure in vivo conditions in this multicentre trial was increased by patients who did not want to participate in a drug-trial, by patients who were treated with anti-depressants in the preceding year and by patients who had been put on a waiting list ( 8 weeks) $(n=25)$. Univariate analyses of variance (ANOVAs) or non-parametric tests did not reveal significant differences for the pretreatment dependent variables or for the demographic variables between these two patient-groups. All patients in the multicentre-trial and in the present project were randomly assigned to conditions.

Before the treatment a pretest was held, after 6 sessions an intermediate test (=midtest) took place, and after 16 sessions ( 16 weeks) a posttest was held. In case all the symptoms of a patient disappeared before the end of the 16 treatment sessions and he/she has had at least nine treatment sessions, a posttest was held and these patients were included in this study $(n=3)$.

\section{Subjects and procedure}

The inclusion criteria were:

(1) a primary DSM-III-R (American Psychiatric Association, 1987) diagnosis of OCD;

(2) not only obsessions;

(3) age between 18 and 65 ;

(4) a duration of OCD for at least one year;

(5) absence of an organic mental disorder, mental retardation or a psychotic disorder;

(6) no cognitive treatment or behavioural treatment in the preceding six months;

(7) no use of anti-depressants. 
Patients were either referred to our departments by general practioners and by mental health agencies or responded to newspaper articles describing the availability of a treatment program for OCD. Seventy-one patients were included in this study. Fourteen patients dropped out; seven in the cognitive therapy condition (20\%) and seven in the self-controlled exposure in vivo condition $(19 \%)$. Patients were screened by a Dutch version of the standardized Anxiety Disorder Interview Schedule [ADIS; Bouman, Scholing, Emmelkamp \& Dijkstra (1987); DiNardo, O’Brien, Barlow, Waddell \& Blanchard (1983)] by an experienced clinical psychologist or an experienced psychiatrist.

The characteristics of the patients who completed the trial are presented in Table 1. Patients were treated as outpatients at the psychiatric outpatient clinic at the Reinier de Graaf Hospital Delft $(n=20)$ or at the outpatient clinic for anxiety disorders at the Psychiatric Centre Amsterdam $(n=37)$.

\section{Therapists}

Therapists were five clinical psychologists and one psychiatrist ( 3 male and 3 female). All six therapists conducted therapy in both treatment conditions. All six therapists were versed in behaviour therapy and had experience with behavioural treatment of OCD. Prior to the start of the study therapists received training in cognitive therapy for OCD.

\section{Treatment}

Both treatments consisted of 16 sessions of approx. $45 \mathrm{~min}$. For both conditions treatment manuals were developed and used to guide the treatment. Weekly group sessions were held with the therapists, where problems that occurred during the treatments were discussed. All therapy sessions were audiotaped and the audiotapes were partly overheard regularly in the weekly group sessions.

Cognitive therapy. The cognitive therapy for OCD used in this study was essentially based on cognitive therapy for depression and anxiety disorders (Beck, 1976; Beck, Emery \& Greenberg, 1985; Salkovskis, 1985). The general strategies are: firstly, to consider the intrusions as stimuli; secondly, to identify the distressing thoughts (negative automatic thoughts); thirdly, to challenge these automatic thoughts; and fourthly, to change these thoughts to non-distressing thoughts and finally, the underlying dysfunctional assumptions were looked for, these beliefs were challenged in the therapy sessions, and this also had to be done by the patient as homework assignments. Care was taken that two potentially bias reasoning styles were addressed, i.e. overestimation of danger and inflated personal responsibility. An important general cognitive technique used by the therapist to challenge the automatic thoughts is the Socratic Dialogue (Beck, 1976). Patients were also instructed to monitor and challenge automatic thoughts in diaries as homework assignments. In the therapy sessions problems with the diary were discussed and worked out, and in each session at least one automatic thought was challenged. After session six behavioural experiments were introduced. The behavioural experiments were mainly used to test out the empirical basis of the dysfunctional assumptions [for further details see van Oppen \& Arntz (1994)].

Table 1. Patients characteristics

\begin{tabular}{|c|c|c|}
\hline & $\begin{array}{c}\text { Cognitive therapy } \\
(n=28)\end{array}$ & $\begin{array}{c}\text { Exposure in vivo } \\
(n=29)\end{array}$ \\
\hline \multicolumn{3}{|l|}{$\operatorname{Sex}$} \\
\hline Men & $46 \%$ & $48 \%$ \\
\hline Women & $54 \%$ & $52 \%$ \\
\hline Mean age* & $34.1(10.8)$ & $35.3(10.1)$ \\
\hline \multicolumn{3}{|l|}{ Marital status } \\
\hline Single & $29 \%$ & $55 \%$ \\
\hline Living together $/$ married & $64 \%$ & $38 \%$ \\
\hline Divorced/widow & $7 \%$ & $7 \%$ \\
\hline \multicolumn{3}{|l|}{ Education } \\
\hline Low & $21 \%$ & $31 \%$ \\
\hline Medium & $61 \%$ & $45 \%$ \\
\hline High & $18 \%$ & $24 \%$ \\
\hline Duration of complaints* & $11.7(9.8)$ & $14.4(11.7)$ \\
\hline
\end{tabular}

*In years; standard deviation in parentheses. 
Self-controlled exposure in vivo with response prevention. In the first treatment session information about the rationale of exposure with response prevention was given. An inventory of the obsessive compulsive avoidance behaviour and of the compulsions was made. After this a hierarchy of obsessive compulsive situations which were mostly avoided or triggered rituals were constructed. All these situations were noted and at each session a number of items of the hierarchy were given as homework tasks. Each session started with a discussion about the performance of the previous homework tasks and new homework tasks were discussed at length; after this patient and therapist agreed on which homework assignment had to be done before the next session. All patients determined the speed at which they worked through the hierarchy by him- or herself. In the first six sessions care was taken that the expectations of disastrous consequences were not discussed. Treatment essentially consisted of two components: self-exposure in vivo and self-imposed response prevention [for further details see Emmelkamp (1982)].

\section{Measures}

In this study the following measures were completed:

(1) The Padua Inventory-Revised [PI-R; Sanavio (1988); Sternberger \& Burns (1990); van Oppen (1992); van Oppen, Hoekstra \& Emmelkamp (1995b)] consists of 41 self-rated items; range 0-164. All items are rated on a 5-point scale from $0=$ not at all to $4=$ very much. The PI-R provided 5 subscales: (i) impulses; (ii) washing; (iii) checking; (iv) rumination; and (v) precision. The validity, reliability and the sensitivity to change of the PI-R are satisfactory (van Oppen et al., 1995b; van Oppen, Emmelkamp, van Balkom \& van Dyck; 1995a).

(2) The Yale Brown Obsessive Compulsive Scale [Y-BOCS; Goodman, Price, Rasmussen, Mazure, Fleischmann, Hill, Heninger \& Charney (1989)] is a clinician-rated scale, consisting of ten items to assess OCD symptom severity; range $0-40$. The therapist scores the items from $0=$ no symptoms to $4=$ severe symptomatology, based on a structured interview. There are two subscales: one for severity of obsessions and one for severity of compulsions. In this study only the total score is used. The reliability and convergent validity of the Y-BOCS are satisfactory (Goodman et al., 1989; Woody, Steketee \& Chambless, 1994). The Y-BOCS is a sensitive treatment outcome measure (van Oppen et al., 1995a).

(3) The Anxiety Discomfort Scale (ADS) is an adapted version of the Watson and Marks (1971) scales. Five main obsessive compulsive targets are rated on a $9(0=$ no uneasiness to $8=$ extreme fear/tension) point scale for anxiety/discomfort by the patient. Thus, the situations differ from patient to patient. The total score is the sum of the score on the 5-items. This scale is sensitive to change after treatment in obsessive compulsives (Emmelkamp, 1982; van Oppen et al., 1995a). In this study the ADS was completed by the patient, an assessor and the therapist. Factor-analysis on these three variables at pretest demonstrated that one factor explained $75.2 \%$ of the variance. So, in this study we pooled the 3 scores and divided the sum by three.

(4) The revised version of the Symptom Checklist [SCL-90-R; Derogatis (1977)] is a multidimensional self-report inventory of current psychopathology. Items are rated on a 5 point scale (scores range from 90 to 450 ).

(5) The Beck Depression Inventory [BDI; Beck, Ward, Mendelson, Mock \& Erbaugh (1961)] consists of 21 -items. Items are rated on a 4 point scale (range 0-63). The total score measures the severity of depressive symptoms. In a Dutch population the validity of this questionnaire is satisfactory (Luteijn \& Bouman, 1988).

(6) The Irrational Belief Inventory [IBI; Koopmans, Sanderman, Timmerman \& Emmelkamp (1994)] is a 50-item questionnaire based on the Irrational Belief Test (Jones, 1968) and the Rational Behavior Inventory (Shorkey \& Whithman, 1977). Items are rated on a 5 point scale $(1=$ strongly disagree to $5=$ strongly agree; range 50-250). The total score of the IBI is a index of general irrational beliefs of the patients.

\section{Data analyses}

Univariate analyses of variance (ANOVAs) or non-parametric tests were run in order to evaluate the significance of the differences between both conditions on the pretest scores and demographic variables. 
Treatment results were analysed with a two (group) by three (time) split-plot design using multivariate and univariate analysis of variance. Two MANOVAs were run: one with the obsessive compulsive measures (Y-BOCS, PI-R and ADS) and the other with the generalized measures (BDI and SCL-90-R) to assess generalization of treatment effects. In case of a multivariate significant time effect ANOVAs for the individual outcome measures were run. One ANOVA with the cognitive measure (IBI) was run to assess cognitive changes. Pre- to posttest paired $t$-tests, with Bonferroni correction, were used to assess changes in time within individual conditions.

Significant multivariate interaction effects were further analysed with ANCOVAs, with the pretest as covariate.

Further, the effect sizes (ES) for improvement on the three obsessive compulsive measures were calculated with the following formula (Cohen, 1988; Shavelson, 1981):

$$
\mathrm{ES}=\frac{x_{2}-x_{1}}{\sqrt{s_{1}^{2}+s_{2}^{2}-2 r_{12} s_{1} s_{2}}}
$$

where $x_{1}=$ pre-scores; $x_{2}=$ post-scores; $s_{1}=$ standard deviation of pre-scores; $s_{2}=$ standard deviation of post-scores; $r_{12}=$ Pearson correlation between pre- and post-scores.

Jacobson and colleagues (Jacobson, Follette \& Revensdorf, 1984; Jacobson \& Truax, 1991) suggested a statistical approach to assess the clinical significance of results achieved. A subject according to Jacobson and colleagues is "recovered" when they met the two-fold criterion for clinically significant change; (i) the reliable change index; and (ii) the determination of recovery (Jacobson \& Truax, 1991). Since calculation of change and determination of recovery are complementary procedures (Steketee \& Chambless, 1992), we investigated both the reliable change index and the determination of recovery.

To determine statistically reliable change Jacobson and his colleagues (1984) proposed a formula for a Reliable Change index (RC), later modified by Christensen and Mendoza (1986). Recently Hageman and Arrindell (1993) proposed a further adjustment of the RC index by improving the pre-post difference scores $\left(\mathrm{RC}_{\mathrm{ID}}\right)$ taking into account regression to the mean. To investigate the change which has occurred after treatment we used this latter $\mathrm{RC}_{\mathrm{ID}}$ index.

The $\mathrm{RC}_{\mathrm{ID}}$ should be $>1.96$. This $\mathrm{RC}_{\mathrm{ID}}$ classifies subjects according to whether or not they had improved reliably, independently of the clinical significance of this improvement. So, in addition to the $\mathrm{RC}_{\mathrm{ID}}$ we determined whether the change was clinically significant (determination of recovery). Given the nature of the Y-BOCS and the ADS, norms for non-clinical samples cannot be determined. Therefore we determined the cutoff point for clinically significant change at two standard deviations from the mean of the OCD patients in this study (Jacobson \& Truax, 1991). For the PI-R data from a normal sample are available (van Oppen, 1992). When the functional and dysfunctional distributions are only slightly overlapping as in our case, Jacobson and Truax (1991) recommend a cutoff point at two standard deviations from the mean of the functional population. Finally, non-parametric tests were run to compare the percentage of recovery of patients between the conditions.

\section{RESULTS}

\section{Pretreatment characteristics}

Results at the pretest are presented in Table 2. The univariate analyses of variance (ANOVAs) did not reveal significant differences for the pretreatment dependent variables except for the ADS. The pretest score of the ADS was significantly higher in the exposure condition $[F(1,55)=3.9$, $P=0.05]$. No significant differences were found between the cognitive and exposure condition on the demographic variables, duration of complaints $[F(1,55)=0.9, P=0.34]$, marital status $\left(\chi^{2}=4.3, d f=2, P=0.11\right)$, age $[F(1,55)=0.2, P=0.67]$, gender $\left(\chi^{2}=0.0, d f=1, P=0.89\right)$ and education $\left(\chi^{2}=1.4, d f=2, P=0.48\right)$. In both conditions the average symptom duration was $>11$ years and the gender ratio was nearly $1: 1$ (see Table 1 ). This is comparable to other studies [see for reviews Marks (1987); Steketee (1993)]. 
Table 2. Descriptive results (means and standard deviations) for cognitive therapy and exposure

\begin{tabular}{|c|c|c|c|c|}
\hline & & Pretest & Midtest & Posttest \\
\hline \multirow{2}{*}{\multicolumn{5}{|c|}{ Obsessive compulsive measures }} \\
\hline & & & \\
\hline Cognitive & $n=28$ & $28.7(5.3)$ & $18.9(8.8)$ & $13.4(9.4)$ \\
\hline Exposure & $n=29$ & $31.4(5.0)$ & $23.8(7.1)$ & $17.9(9.0)$ \\
\hline \multicolumn{5}{|c|}{$P I-R$} \\
\hline Cognitive & $n=28$ & $72.6(25.6)$ & $62.7(27.9)$ & $51.5(27.8)$ \\
\hline Exposure & $n=29$ & $69.9(19.6)$ & $63.3(22.7)$ & $58.1(23.5)$ \\
\hline \multicolumn{5}{|c|}{$Y-B O C S$} \\
\hline Cognitive & $n=28$ & $24.1(5.5)$ & $19.3(9.0)$ & $13.3(8.5)$ \\
\hline Exposure & $n=29$ & $25.4(7.0)$ & $19.2(7.5)$ & $17.3(8.3)$ \\
\hline \multirow{2}{*}{\multicolumn{5}{|c|}{$\begin{array}{l}\text { Generalized measures } \\
S C L-90-R\end{array}$}} \\
\hline & & & & \\
\hline Cognitive & $n=28$ & $197.1(70.8)$ & $184.7(59.2)$ & $166.3(58.8)$ \\
\hline Exposure & $n=29$ & $192.8(47.3)$ & $169.3(38.2)$ & $178.3(48.7)$ \\
\hline \multicolumn{5}{|l|}{$B D I$} \\
\hline Cognitive & $n=27$ & $16.3(10.1)$ & $14.3(10.1)$ & $11.3(8.7)$ \\
\hline Exposure & $n=29$ & $16.6(7.9)$ & $13.3(6.3)$ & $12.9(8.5)$ \\
\hline \multicolumn{5}{|c|}{$\begin{array}{l}\text { Cognitions measure } \\
I B I\end{array}$} \\
\hline Cognitive & $n=27$ & $158.3(18.0)$ & $152.4(14.2)$ & $149.6(21.1)$ \\
\hline Exposure & $n=28$ & $163.2(19.1)$ & $156.5(13.8)$ & $159.2(17.4)$ \\
\hline
\end{tabular}

\section{Overall and differential treatment effects}

Descriptive results for both treatments on the outcome variables are shown in Table 2 and Fig. 1. Results of evaluation MANOVA's assumptions (Tabachnick \& Fidell, 1989) of normality, linearity and multicollinearity were satisfactory. MANOVAs revealed a significant multivariate time effect on the obsessive compulsive measures (Y-BOCS, PI-R and ADS) $[F(6,50)=32.9, P<0.000]$ and
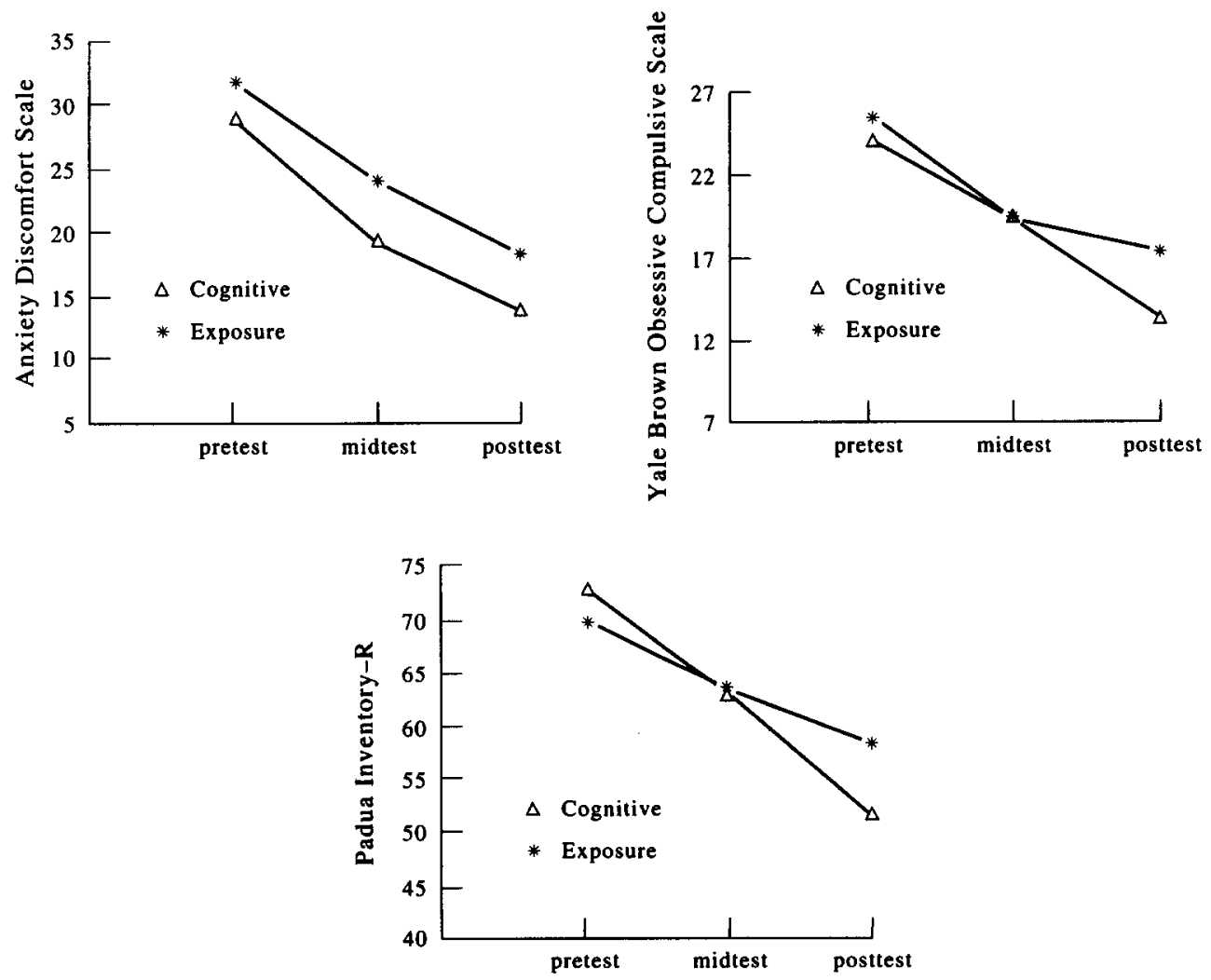

Fig. 1. Improvements on the obsessive compulsive measures for both conditions. 
Table 3. ANCOVAs for differential treatment effects with the pretest as covariate

\begin{tabular}{|c|c|c|}
\hline & Pretest-midtest & Pretest-posttest \\
\hline & .54 & $F(1.54)$ \\
\hline $\mathbf{P}-\mathrm{BC}$ & l) $=0.22$, & $F(1,5$ \\
\hline & $F$ & $F(1$ \\
\hline SCI & $F(1,54)=1.57, P=0.22$ & $F(1,54)=1.54, P=0.22$ \\
\hline $\mathrm{BDI}$ & $F(1,54)=0.51, P=0.48$ & $F(1.53)=0.61, P=0.44$ \\
\hline
\end{tabular}

Table 4. Effect sizes for improvement

\begin{tabular}{lcc}
\hline & $\begin{array}{c}\text { Cognitive therapy } \\
(n=28)\end{array}$ & $\begin{array}{c}\text { Exposure in rito } \\
(n=29)\end{array}$ \\
\hline ADS & 1.90 & 1.76 \\
Y-BOCS & 1.42 & 1.03 \\
PI-R & 0.92 & 0.63 \\
\hline
\end{tabular}

on the generalized measures (SCL-90-R and BDI) $[F(4,51)=5.6, P<0.002]$. Subsequent ANOVAs yielded significant time effects on all measures. The ANOVA on the cognitive measure (IBI) also revealed a significant time effect $[F(2,53), P<0.008]$. Post hoc $t$-tests were done to investigate changes between pre- and posttest in each treatment group separately, with alpha set at 0.025 (Bonferroni correction). Both conditions improved significantly on almost all variables. Only on the SCL-90-R $(t=1.45, d f=28, P=0.16)$ and on the IBI $(t=1.60, d f=28, P=0.12)$ no time effects were demonstrated in the exposure condition. Moreover, both MANOVAs also revealed a significant multivariate interaction effect on the obsessive compulsive measures $[F(6,50)=2.7$, $P<0.03]$ and on the generalized measures $[F(4,51)=3.1, P<0.03]$. These results suggested a greater efficacy of cognitive therapy in comparison to exposure in vivo.

Results of evaluation ANCOVAs assumptions (Tabachnick \& Fidell, 1989) of normality of sampling distributions, linearity, homogeneity of variance, homogeneity of regression and reliability of covariates were satisfactory. Significant interaction effects were further analysed with ANCOVAs, with the pretest score as covariate. These results can be seen from Table 3 . Neither the ANCOVAs after the first treatment period nor the ANCOVAs after the second treatment period yielded significant differential treatment effects. Finally, no significant multivariate between group differences were found.

The effect sizes for improvement on the obsessive compulsive measures are presented in Table 4: these effect sizes were slightly higher in the cognitive therapy condition as compared to the exposure condition.

\section{Reliable change and clinical significance}

The $\mathrm{RC}_{\mathrm{ID}}$ on the ADS was $\geqslant 3$, on the $\mathrm{Y}$-BOCS $\geqslant 6$ and on the PI-R $>9$. The cutoff point for clinically significant change (Jacobson \& Truax, 1991) was for the ADS 19, for the Y-BOCS 12 and for the PI-R 53. Patients were rated as recovered when the score fulfilled the criteria for $\mathrm{RC}_{\mathrm{ID}}$ as well as for a clinically significant change. For an overview of the percentages of the reliable change index and the recovered index on the obsessive compulsive measures see Table 5. As can be seen, the percentage of patients who fulfilled the reliable change index and the recovered index were for all measures higher in the cognitive therapy condition than in the exposure condition. Statistically significant differences between the treatment conditions were found between the percentage of patients who recovered on the PI-R $\left(\chi^{2}=5.2, d f=1, P<0.03\right)$, on the Y-BOCS $\left(\chi^{2}=4.1, d f=1, P<0.05\right)$ and on a minimum of two measures $\left(\chi^{2}=6.5, d f=1, P<0.02\right)$. A trend was found on percentage patients, who recovered on all measures $\left(\chi^{2}=3.4, d f=1, P<0.07\right)$, while no statistically significant difference was found on percentage patients who recovered on the ADS $\left(\chi^{2}=0.6, d f=1, P<0.64\right)$.

Table 5. Percentage reliable change index and the recovered index on the obsessive compulsive measures

\begin{tabular}{lccccc}
\hline & \multicolumn{2}{c}{ Reliable change } & & \multicolumn{2}{c}{ Recovered } \\
\cline { 2 - 3 } \cline { 5 - 6 } & Cognitive & Exposure & Cognitive & Exposure \\
\hline PI-R & 75 & 62 & & 57 & 31 \\
Y-BOCS & 75 & 66 & & 50 & 28 \\
ADS & 96 & 90 & 68 & 62 \\
On a minimum of two measures & 75 & 72 & & 61 & 48 \\
On all three measures & 68 & 48 & & 39 & 17 \\
\hline
\end{tabular}




\section{Subgroups of $O C D$}

Post -hoc a number of explorative analyses were done. Firstly, we investigated whether there are differences in efficacy between cognitive therapy and exposure in vivo for the subgroup of "checkers". Several experiments (Röper, Rachman \& Hodgson, 1973; Röper \& Rachman, 1976; Rachman \& Hodgson, 1980) demonstrated the role of responsibility in compulsive checking, but the sense of responsibility seemed less relevant in the case of cleaners (Rachman, 1993a). The issue of responsibility was explicitly dealt with in our cognitive therapy condition (van Oppen \& Arntz, 1994). So, we expected that the subgroup checkers would profit more from cognitive therapy than from exposure in vivo. Patients were rated by the first three authors to which category they belonged. These categories were: (a) washers; (b) checkers; (c) a combination of washing and checking; and (d) other obsessive compulsive complaints. Seven patients were rated as "checkers" in the cognitive therapy condition vs ten patients in the exposure in vivo condition. Post-hoc ANCOVAs, with the pretest as covariate, did not reveal any significant between group differences on the three obsessive compulsive measures for the subcategory "checkers". These analyses revealed a trend on the Y-BOCS $[F(1,14)=3.4, P<0.10]$, in favour of cognitive therapy.

Secondly, we investigated whether there were differences in efficacy between cognitive therapy and exposure in vivo on the subscales obsessions and compulsions of the Y-BOCS. It has been noted in the literature that cognitive therapy may be effective in dealing with obsessions (Emmelkamp, 1987; Rachman, 1993b; Salkovskis \& Warwick, 1985; Salkovskis \& Westbrook, 1989). However, ANCOVAs revealed no significant differences in efficacy between the treatment conditions on the Y-BOCS-obsessions $[F(1,52)=0.0, P=0.44]$, nor on the Y-BOCS-compulsions $[F(1,51)=0.5$, $P=0.49]$

\section{Drop-outs}

In each treatment conditions 7 patients dropped out: $20 \%$ in the cognitive therapy and $19 \%$ in the exposure in vivo group. The reasons for drop-outs were: a lack of improvement $(n=5)$, the depressive symptoms became more important than the obsessive compulsive symptoms $(n=2)$, the symptoms disappeared before sessions nine $(n=2)$, practical reasons unrelated to the treatment $(n=3)$, or remained unclear $(n=2)$. The ANOVAs did not reveal significant differences on the outcome variables between completers and drop-outs at pretest. Further, no significant differences on demographic variables were found between completers and drop-outs. The analyses revealed only a trend on the variable duration of complaints $[F(1,69)=3.0, P<0.09]$. The completers had a mean duration of complaints of 12.7 year $(\mathrm{SD}=10.8)$ and the drop-outs of 7.6 year $(\mathrm{SD}=4.7)$.

Further, all drop-outs were assessed on the Y-BOCS at the last treatment session. Because 2 patients dropped out after the first session, data (minimal 2 Y-BOCS scores) was available for 12 drop-outs. A post-hoc paired $t$-test revealed significant improvement for the drop-outs on the Y-BOCS $(t=2.2, d f=11, P<0.05)$. No difference was found on the Y-BOCS of the drop-outs between cognitive therapy and exposure in vivo.

\section{DISCUSSION}

This is the first controlled study that demonstrates cognitive therapy along the lines of Beck and Salkovskis specifically developed for OCD (van Oppen \& Arnzt, 1994) to be an effective treatment for obsessive compulsive disorder. Both cognitive therapy and exposure in vivo led to statistically as well as clinically significant improvement. Patients treated with cognitive therapy improved significantly on all variables, and patients treated with exposure in vivo on almost all variables, except on the SCL-90-R and on the IBI. The demonstrated efficacy of exposure in vivo on the obsessive compulsive measures are in line with other recent outcome studies of exposure in vivo in OCD (Emmelkamp \& Beens, 1991; Emmelkamp et al., 1988).

Multivariate significant interaction effects on the obsessive compulsive measures and on the generalized measures suggested a greater efficacy of cognitive therapy in comparison to exposure in vivo. However, these differences did not stand up in separate ANCOVAs in which initial differences between conditions were taken into account. From Table 3 it can be seen that the ANCOVAs (with the pretest as covariate) revealed a trend on the Y-BOCS and on the PI-R in 
favour of cognitive therapy. Possibly, the MANOVAs which consider dependent variables in combination were more powerful in determining significant differences then subsequent separate ANCOVAs. The differences in effect size and in the percentage of recovered patients suggest that cognitive therapy might be superior to exposure in vivo.

In recent years, composite variables are frequently used in treatment outcome studies to increase the statistical power. But, given the low correlations between the PI-R, the Y-BOCS and the ADS (van Oppen et al., 1995a) we did not use a composite-measure because these measures seem to assess relatively different features of OCD.

In both conditions the effect sizes for improvement on the obsessive compulsive measures were large, except for the improvement on the PI-R in the exposure condition. The effect sizes on the obsessive compulsive measures were all larger in the cognitive therapy than in the exposure condition.

To address the issue of clinical relevance, both reliable change indexes and recovered indexes were determined. In both treatment conditions a considerable percentage of the patients demonstrated a reliable change and was rated as "recovered" on the PI-R, the Y-BOCS and on the ADS. Significantly more patients were rated as reliable changed or as "recovered" in the cognitive therapy on the PI-R, on the Y-BOCS and on a minimum of two measures. No significant differences were found on the ADS and the percentage of patients who recovered on all three measures. These findings are in line with the multivariate significant differences, suggesting a possible superiority of cognitive therapy in comparison to exposure in vivo.

In contrast to the present study, Emmelkamp and his colleagues (Emmelkamp et al., 1988; Emmelkamp \& Beens, 1991) did not find differences between cognitive therapy and exposure in vivo on the obsessive compulsive measures. Since the effects obtained for exposure in vivo are comparable to those found in other studies, these findings cannot be explained by a lower effect of exposure in vivo. In a meta-analysis of van Balkom, van Oppen, Vermeulen, Nauta, Vorst and van Dyck (1994) the mean effect size for exposure was 1.47 , mostly determined by the ADS, which is roughly comparable to the effect sizes in the present study. Another explanation might be the large $n \mathrm{~s}$ in both conditions in the present study. Large $n \mathrm{~s}$ solve the power problem which has frequently plagued outcome studies in OCD. Finally, the differences in outcome between the present study and those by Emmelkamp and his colleagues might be related to the particular form of cognitive therapy used in this study. We used cognitive therapy along the lines of Beck and Salkovskis which also included behavioural experiments after session six, whereas Emmelkamp and his colleagues used RET (Ellis, 1962) and excluded all behavioural exercises. Further, in the cognitive therapy along the lines of Beck the Socratic dialogue is an important therapist's technique and attention is paid to idiosyncratic assumptions instead of the 11 basic beliefs of RET. And finally, the cognitive therapy used in this study, which was specifically developed for OCD, mainly focused on: (i) estimation of catastrophes and on (ii) the estimation of personal responsibility (van Oppen \& Arntz, 1994).

The ANCOVAs after the first treatment period (six sessions), did not reveal any significant differential treatment effects. Thus, cognitive therapy without behavioural experiments was as effective as self-controlled exposure in vivo with response prevention without cognitive elements. These findings are consistent with the findings of Emmelkamp and his colleagues (Emmelkamp et al., 1988; Emmelkamp \& Beens, 1991). It has to be noticed that Emmelkamp et al. (1988) found that the efficacy of cognitive therapy was greater than the efficacy of exposure in vivo on a measure of depression. Although we did not find similar results on the BDI, the multivariate differences on the generalized measures are in line with these previous findings.

Does cognitive therapy change cognitions, whereas exposure in vivo does not? Only in the cognitive condition a significant time effect was found on the index of irrational cognitions, which supports the construct validity of cognitive therapy. However, this difference on the IBI was not statistically significant between the conditions. We found significant correlations between the improvement on the IBI on the one hand and improvement on the Y-BOCS $(r=0.47, P<0.001)$; ADS $(r=0.45, P<0.001)$ and on the PI-R $(r=0.55, P<0.001)$ on the other. The same results were found by Emmelkamp and his colleagues (Emmelkamp \& Beens, 1991; Emmelkamp et al., 1988). Data from a normal sample demonstrated that this normal sample has less irrational cognitions $(3$ mean $=139.2, \mathrm{SD}=18.5$ and $q$ mean $=143.3, \mathrm{SD}=16,4)$ than the OCD sample in 
this study (see Table 2) (Koopmans et al., 1994). It has to be noticed that the score of the IBI an index is of general irrational beliefs. Additional research is needed to develop and to investigate measures which assess the more specific cognitions related to OCD.

Post-hoc comparisons did not reveal any significant difference between cognitive therapy and exposure in vivo on the obsessive compulsive measures for the subgroup "checkers". This may be due to the small $n$ s for each subgroup per condition. Further, even though the overestimation of responsibility was an important focus of the cognitive therapy, other issues were also addressed such as the estimation of chance of catastrophe (van Oppen \& Arntz, 1994). The responsibility issue deserves further empirical study. A challenging task for further research is to investigate which subgroup of OCD patients profit from which form of therapy. We further investigated whether there were differences between the efficacy of cognitive therapy and exposure in vivo on obsessions on the one hand and compulsions on the other. Explorative analyses did not reveal significant differences between the treatment conditions on the subscales obsessions and compulsions of the Y-BOCS. As patients with obsessions only were excluded from this study, an explanation for these findings could be that the obsessions of patients who have also compulsions are different from the obsessions of patients with only obsessions. Additional research is needed to investigate whether cognitive therapy is more effective than exposure in vivo with pure obsessional patients.

No significant differences were found between completers and drop-outs on demographic variables or pretest scores. Even though no significant differences were found on the duration of obsessive compulsive complaints, drop-outs appeared to have a shorter duration of obsessive compulsive complaints than completers $(P<0.09)$. Although Hansen, Hoogduin, Schaap and de Haan (1992) found at pretest a significantly lower score on a OCD measure we could not replicate those findings. The results of the improvement of the drop-outs are consistent with the recent findings of improvement of social phobic drop-outs (Scholing \& Emmelkamp, 1993a, 1993b).

Taking these results together, this study demonstrates the efficacy of cognitive therapy along the lines of Beck (1976) and Salkovskis (1985). The present results suggest that this form of cognitive therapy, which also includes behavioural experiments, may be even more effective than exposure in vivo. However, the long term effects of exposure are well established (Steketee, 1993) whereas further studies are needed to investigate the long term effects of cognitive therapy with OCD.

Acknowledgements - The authors wish to thank Walter Arts, Joost Beek, Jette Kiestra, Henriette Kuipers, Marion Nadort and Rudi Severijns for the efforts as therapists in this study, Arnoud Arntz for his valuable supervisions of cognitive therapy and his enthusiastic support, and Paul Emmelkamp and Arnoud Arntz for their thoughtful comments on an earlier version of this manuscript.

\section{REFERENCES}

American Psychiatric Association (1987). Diagnostic and statistical manual of mental disorders (3rd revised edn). Washington. DC: American Psychiatric Association.

Balkom, A. J. L. M. van, Oppen, P. van, Vermeulen, A. W. A., Nauta, M. M. C., Vorst, H. C. M. \& van Dyck, R. (1994). A meta-analysis on the treatment of obsessive compulsive disorder: A comparison of antidepressants, behavior and cognitive therapy. Clinical psychology review, 14, 359-381.

Beck, A. T. (1976). Cognitive therapy and the emotional disorder. New York: International Universities Press.

Beck, A. T., Emery, G. \& Greenberg, R. L. (1985). Anxiety disorders and phobias: A cognitive perspective. New York: Basic Books.

Beck, A. T., Ward, C. H., Mendelson, M., Mock, J. E. \& Erbaugh, J. K. (1961). An inventory for measuring depression Archives of General Psychiatry, 4, 561-571.

Bouman, T. K., Scholing, A., Emmelkamp, P. M. G. \& Dijkstra, W. (1987). Anxiety Disorders Interview' Schedule (ADIS) (intern report). Groningen: University of Groningen, Department of Clinical Psychology.

Christensen, L. \& Mendoza, J. L. (1986). A method of assessing change in a single subject: An alteration of the RC index. Behavior Therapy, 17, 305-308.

Cohen, J. (1988). Statistical power analysis for the hehavioral sciences. Hillsdale: Lawrence Erlbaum Associates.

DiNardo, P. A., O'Brien, G. T., Barlow, D. H., Waddell, M. T. \& Blanchard, E. B. (1983). Reliability of DSM-III anxiety disorders categories using a new structured interview. Archives of General Psychiatry, 40, 1070-1075.

Derogatis, L. R. (1977). SCL-90: Administration, scoring and procedures manual -I for the Revised version. Baltimore, MD: Johns Hopkins University School of Medicine, Clinical Psychometrics Research Unit.

Ellis, A. (1962). Reason and emotion in psychotherapy. New York: Lyle-Stuart.

Emmelkamp, P. M. G. (1982). Phobic and obsessive-compulsive disorders: theory, research, and practice. 2. New York: Plenum Press.

Emmelkamp, P. M. G. (1987). Obsessive-compulsive disorders. In: Michelson, L. and Ascher, L. M. (Eds) Anxiety and stress disorders: cognitive-behavioral assessment and treatment. New York: Wiley.

Emmelkamp, P. M. G. \& Beens, H. (1991). Cognitive therapy with obsessive-compulsive patients: a comparative evaluation. Behaviour Research and Therapy, 29, 293-300. 
Emmelkamp, P. M. G., van der Helm, M., van Zanten, B. \& Plochg, I. (1980). Contributions of self-instructional training to the effectiveness of exposure in vivo: a comparison with obsessive-compulsive patients. Behaviour Research and Therapy, 18, 61-66.

Emmelkamp, P. M. G. \& Kraanen, J. (1977). Therapist controlled exposure in vivo versus self-controlled exposure in vivo: a comparison with obsessive-compulsive patients. Behaviour Research and Therapy, 15, 491-495.

Emmelkamp, P. M. G., van Linden van den Heuvell, C., Ruphan, M. \& Sanderman, R. (1989). Home-based treatment of obsessive-compulsive patients: Intersession interval and therapist involvement. Behaviour Research \& Therapy, 18. $61-66$.

Emmelkamp, P. M. G., Visser, S. \& Hoekstra, R. (1988). Cognitive therapy vs exposure in the treatment of obsessivecompulsives. Cognitive Therapy and Research, 12, 103-114.

Goodman, W. K., Price, L. H., Rasmussen, S. A., Mazure, C., Delgado, P., Heninger, G. R. \& Charney, D. S. (1989). The Yale-Brown Obsessive Compulsive Scale: II validity. Archives of General Psychiatry, 46, $1012-1016$

Goodman, W. K., Price, L. H., Rasmussen, S. A., Mazure C., Fleischmann, R., Hill, C. L., Heninger, G. R. \& Charney, D. S. (1989). The Yale-Brown Obsessive-Compulsive Scale I: development, use, and reliability. Archives of General Psychiatry, 46, 1006-1011.

Hageman, W. J. J. M. \& Arrindell, W. A. (1993). A further refinement of the reliable change (RC) index by improving the pre-post difference score: introducing $\mathrm{RC}_{\mathrm{ID}}$. Behaviour Research \& Therapy, 31, 693-700.

Hansen, A. M. D., Hoogdium, C. A. L., Schaap, C. and Haan, E. de (1992). Do drop-outs differ from successfully treated obsessive-compulsives? Behaviour Research and Therapy, 10,111-117.

Hollon, S. D. \& Beck, A. T. (1994). Cognitive and cognitive behavioral therapies. In: Bergin, A. E. \& Garfield, S. L. (Eds) Handbook of psychotherapy and behavior change (4th edn pp. 428-466).

Jacobson. N. S., Follette, W. C. \& Revensdorf, D. (1984). Psychotherapy outcome research: Methods for reporting variability and evaluating clinical significance. Behavior Therapy, 15, 336-352.

Jacobson, N. S. \& Truax, P. (1991). Clinical significance: a statistical approach to defining meaningful change in psychotherapy research. Journal of Consulting and Clinical Psychology, 59, 12-19.

Jones, R (1968). A factored measure of Ellis' irrational beliefs system with personality maladjustment correlates. Dissertation Abstracts International, 29, 4379-4380.

Kendall, P. C. (1983). Methodology and cognitive-behavioral assessment. Behavioural Psychotherapy, 11, $285-301$.

Koopmans, P. C., Sanderman, R., Timmerman, I. \& Emmelkamp, P. M. G. (1994). The Irrational Beliefs Inventory: Development and psychometric evaluation. European Journal of Psychological Assessment, in press.

Luteijn, F. \& Bouman, T. K. (1988). De validiteit van Beck' Depression Inventory. Nederlands Tijdschrift voor de Psychologie, 43, 340-343.

Margraf, J., Barlow, D. H., Clark, D. M. \& Telch, M. J. (1993). Psychological treatment of panic: work in progress on outcome, active ingredients, and follow up. Behaviour Research \& Therapy, 31, 1-8.

Marks, I. M. (1987). Fears, phobias and rituals. Panic, anxiety and their disorders. New York: Oxford University Press

McFall, M. E. \& Wollersheim, J. P. (1979). Obsessive-compulsive neurosis: A cognitive-behavioral formulation and approach to treatment. Cognitive Therapy and Research, 3, 333-348.

Meichenbaum, D. H. (1975). Self-instructional methods. In Kanver, F. H. \& Goldstein, A. P. (Eds) Helping people change New York: Pergamon.

Oppen, P. van (1992). Obsessions and compulsions: Dimensional structure, reliability, convergent and divergent validity of the Padua Inventory. Behaviour Research \& Therapy, 30, 631-637.

Oppen, P. van \& Arntz, A. (1994). Cognitive therapy for obsessive-compulsive disorder. Behaviour Research \& Therapy, 32, 79-87.

Oppen, P. van, Emmelkamp, P. M. G., Balkom, A. J. L. M. \& van Dyck, R. (1995a). The sensitivity to change of measures for obsessive-compulsive disorder. Journal of Anxiety Disorders, in press.

Oppen, P. van, Hoekstra, R. J. \& Emmelkamp, P. M. G. (1995b). The structure of obsessive compulsive symptoms. Behaviour Research \& Therapy, 33, 15-23.

Rachman, S. (1993a). Obsessions, compulsions and inflated responsibility. Paper presented at the European congress of behaviour \& cognitive therapy, London: 21-25 September 1993.

Rachman, S. (1993b). Obsessions, responsibility and guilt. Behaviour Research \& Therapy, 31, 149-154.

Rachman, S. \& Hodgson, R. J. (1980). Obsessions and compulsions. New York: Prentice Hall.

Rasmussen, S. A. \& Tsuang, M. T. (1986). Clinical characteristics and family history in DSM-III obsessive-compulsive disorder. American Journal of Psychiatry, 143, 317-322.

Röper, G. \& Rachman, S. (1976). Obsessional-compulsive checking: experimental replication and development. Behaviour Research and Therapy, 14, 25-32.

Röper, G., Rachman, S. \& Hodgson, R. (1973). An experiment on obsessional checking. Behaviour Research and Therapy, II, $271-277$.

Sanavio, E. (1988). Obsessions and compulsions: the Padua Inventory. Behaviour Research and Therapv, 26, $167 \cdots 177$

Salkovskis, P. M. (1985). Obsessional-compulsive problems: a cognitive-behavioural analysis. Behaviour Research and Therapy, 23, 571-583.

Salkovskis, P. M. \& Warwick, H. M. C. (1985). Cognitive therapy of obsessive-compulsive disorder: treating treatment failures. Behavioural Psychotherapy, 13, 243-255.

Salkovskis, P. M. \& Westbrook, D. (1989). Behaviour therapy and obsessional ruminations: can failure be turned into success? Behaviour Research and Therapy, 27, 149-160.

Scholing, A. \& Emmelkamp, P. M. G. (1993a). Cognitive and behavioural treatments of fear of blushing, sweating, or trembling. Behaviour Research \& Therapy, 31, 155-170.

Scholing, A. \& Emmelkamp, P. M. G. (1993b). Exposure with and without cognitive therapy for generalized social phobia effects of individual and group treatment. Behaviour Research \& Therapy, 31, 667-681

Shavelson, R. J. (1981). Statistical reasoning for the behavioral sciences. Boston: Allyn \& Bacon.

Shorkey, C. T. \& Whiteman, V. L. (1977). Development of the Rational Behavior Inventory: initial validity and reliability. Educational and Psychological Measurement, 37, 527-534. 
Sternberger, L. G. \& Burns, G. L. (1990). Obsessions and compulsions: psychometric properties of the Padua Inventory with an American college population. Behaviour Research and Therapy, 28, 341-345.

Steketee, G. S. (1993). Treatment of obsessive-compulsive disorder. New York: Guilford.

Steketee, G. \& Chambless, D. L. (1992). Methodological issues in prediction of treatment outcome. Clinical Psychology Review, 12, 387-400.

Tabachnick, B. G. \& Fidell, L. S. (1989). Using multivariate statistics (2nd edn). New York: Harper Collins.

Watson, J. P. \& Marks, I. M. (1971). Relevant and irrelevant fear in flooding-A crossover study of phobic patients. Behavior Therapy, 2, 275-293.

Woody, S. R., Steketee, G. \& Chambless, D. L. (1994). Measures for obsessive compulsive disorder: the Yale-Brown Obsessive Compulsive Scale and the Symptom Checklist-90-R. Manuscript submitted for publication. 